\title{
Nanomaterials-Based Approaches for the Modulation of Sodium Bicarbonate Cotransporters
}

\author{
Jeong Hee Hong \\ Department of Physiology, College of Medicine, Gachon University, 191 Hambakmeoro, Yeonsu-gu, Incheon 406-799, Republic of Korea
}

Correspondence should be addressed to Jeong Hee Hong; minicleo@gachon.ac.kr

Received 1 May 2015; Accepted 6 July 2015

Academic Editor: Yong Ho Kim

Copyright (C) 2015 Jeong Hee Hong. This is an open access article distributed under the Creative Commons Attribution License, which permits unrestricted use, distribution, and reproduction in any medium, provided the original work is properly cited.

\begin{abstract}
$\mathrm{HCO}_{3}{ }^{-}$and fluid secretion are major functions of all epithelia, and alterations in $\mathrm{HCO}_{3}{ }^{-}$secretion by sodium bicarbonate cotransporters are associated with many epithelial diseases, such as renal, ocular, and dental abnormalities. Electrolyte and fluid exits are synergistically mediated by the intracellular second messengers, cAMP and $\mathrm{Ca}^{2+}$, and this raises the possibility that ion transporters are involved in simple secretion and more complicated forms of regulation. Evidence indicates that $\mathrm{HCO}_{3}{ }^{-}$transport is regulated by the assemblage of $\mathrm{Na}^{+}-\mathrm{HCO}_{3}{ }^{-}$cotransporters (NBCs) into complexes by multiple regulatory factors. Recently the specific regulatory functions of factors that interact with NBCel, especially NBCel-B, have been elucidated. In this review, I focus on the structural characteristics of electrogenic NBCel, pathophysiology of NBCel, and molecular mechanisms responsible for transporter regulation. Moreover I propose the possibility to apply nanomaterials combined with regulatory factors for modulating the activity of NBC transporters as a potential development of therapeutic drug.
\end{abstract}

\section{Introduction}

Sodium bicarbonate cotransporters (NBCs) play crucial roles in the regulation of systemic acid/base balance, the absorption and secretion of bicarbonate $\left(\mathrm{HCO}_{3}{ }^{-}\right)$, and the maintenance of electrolyte homeostasis in epithelia. The NBCs are members of the $\mathrm{Na}^{+}$-coupled bicarbonate transporter (NCBT) superfamily, which includes electrogenic NBCs (NBCe1 and NBCe2), electroneutral NBCs (NBCn1 and $\mathrm{NBCn} 2$ ), and $\mathrm{Na}^{+}$-dependent $\mathrm{Cl}^{-}-\mathrm{HCO}_{3}{ }^{-}$exchanger (NDCBE) [1]. Since NBC was identified functionally in kidney proximal tubules [2], NBCel has been identified with five splice variants NBCel-A through NBCel-E and categorized to three splice variants, NBCel-A, NBCel-B, and NBCel-C, which differ at their $\mathrm{N}$ - or C-termini in human and rodents $[1,3]$.

NBCel proteins are coded by the SLC4A4 gene [4], and NBCel-A, which is also known as $\mathrm{kNBCl}$, is predominantly expressed in kidney [5] in the basolateral membrane to mediate $\mathrm{HCO}_{3}{ }^{-}$efflux $[1,6]$ and play a role in transepithelial $\mathrm{HCO}_{3}{ }^{-}$reabsorption. NBCel-A mediates the apparent $1: 3$ cotransport of $\mathrm{Na}^{+}$and $\mathrm{HCO}_{3}{ }^{-}$in proximal tubules [7] but exhibits $1: 2$ stoichiometry in collecting ducts $[1,8]$. The stoichiometry of NBCel-A is regulated by cell type [8], cytosolic $\mathrm{Ca}^{2+}$ concentration [9], and PKA phosphorylation of C-terminus [10]. NBCel-B plays a critical role by mediating basolateral $\mathrm{HCO}_{3}{ }^{-}$influx to accumulate intracellular $\mathrm{HCO}_{3}{ }^{-}$ and facilitate $\mathrm{HCO}_{3}{ }^{-}$secretion to the lumen. Furthermore, it is expressed ubiquitously in basolateral membrane of epithelia and is expressed at especially high levels in pancreas (known as pNBCl) [5, 11-14]. NBCel-C is exclusively expressed in brain (also known as bNBC1), especially in glial cells within the Purkinje cell layer [15], and has the longest amino acid sequence of the three variants [16]. Consistent with several reports, the stoichiometry of NBCel depends on the splice variant, cell type, and the cell environment $[8,9,17$ 19]. NBCs and their derivatives are also involved in many other tissues including salivary glands [20-22], eye [23], intestine [24-26], heart [15,27], tooth [28, 29], and airway submucosal glands cell line Calu-3 [30]. Here I discuss the characteristics and pathophysiology of electrogenic NBCe1 expressed in basolateral membrane close to blood vessel 
and molecular mechanisms of regulatory factors for various potentials of nanosized drug in the modulation of ion transporters.

\section{Pathophysiology of NBCe1}

Cells regulate electrolyte composition and intracellular $\mathrm{pH}$ via the transport of $\mathrm{H}^{+}$and $\mathrm{HCO}_{3}{ }^{-}$. Vectorial transport in epithelia and altered ion secretion, especially of $\mathrm{HCO}_{3}{ }^{-}$, are associated with a wide range of dysfunctions and diseases [31, 32]. Metabolic changes caused by ischemia and reperfusion induce intracellular acidosis due to the generation of $\mathrm{H}^{+}$, which activates $\mathrm{Na}^{+}-\mathrm{H}^{+}$exchanger (NHE) and $\mathrm{NBC}$ and subsequently increases intracellular $\mathrm{Na}^{+}$concentrations [33]. Accordingly, transporter mutations cause many types of diseases. For example, the hyperactive NBCel during reperfusion leads to $\mathrm{Na}^{+}$and $\mathrm{Ca}^{2+}$ overloading and myocardial damage [33], whereas impaired sodium reabsorption caused by gentamicin-induced nephropathy is probably due to the downregulation of sodium transporters, such as NBC and NHE3, suggesting decreased activity of sodium transporters in rat proximal nephrons [34]. Furthermore, inactivating mutation of NBCel was observed to be associated with severe proximal renal tubular acidosis accompanied by ocular abnormalities [35-37] and severe growth retardation [36]. The maintenance of NBCel activity may be essential for the homeostasis of ocular tissues abundantly expressing NBCe1 [38]. Abnormal surface expression of NBCel-B may cause migraine, which suggests that defective functions of NBCe1 are associated with pathophysiologic effects in the brain [39]. Moreover, NBCel-A and NBCel-B are involved in insulin secretion by rat pancreatic islet cells [40]. Insulin-mediated tyrosine kinase enhances $\mathrm{Na}^{+}$absorption by stimulating NBCel in renal proximal tubules [41]. For this reason, hyperinsulinemia could be a risk factor of hypertension via the activation of NBCs. In tooth ameloblasts and papillary layer cells, the expression of NBCel depends on developmental stage [42]. Furthermore, the altered expression of NBCel is associated with the maturation of enamel, which suggests a critical evaluation of the functions of transporters in tooth mineralization is required.

\section{Splice Variants of NBCe1 in Human}

NBCe1-A and NBCe1-B share 93\% homology. They differ at $\mathrm{N}$-termini; that is, the $41 \mathrm{~N}$-terminus of NBCel-A is replaced by 85 amino acids in the $\mathrm{B}$ variant. The $\mathrm{C}$ variant differs at its C-terminus in which 46 amino acids of the $\mathrm{A}$ and $\mathrm{B}$ variants are replaced with 61 amino acids. In the NBCel-B variant, of the 85 amino acids, $50 \%$ are charged residues whereas in the A variant only $22 \%$ of these amino acids are charged. Although all the three variants have similar ion and voltage dependencies and plasma membrane expression patterns in oocytes [43], the transporter activity of NBCel-A is much higher than those of the other two variants. This higher activity of NBCel-A is due to its unique amino terminus and not due to its plasma membrane expressional differences or differences in voltage/ion dependencies [43]. It has been addressed that N-termini of NBCel-B and NBCel-C variants would be included autoinhibitory domains (AID) $[1,43,44]$. The minor isoforms NBCel-D and NBCel-E are deleted a 27 bp segment within the cytosolic N-termini [3]. The physiological significance of three variants has been determined to be unclear. The cytosolic C-terminus is known to have important roles in membrane expression of NBCel transporter including interactions with cytosolic carbonic anhydrase II (CA II) $[45,46]$. Vince et al. addressed the fact that CA II binds to the acidic DADD motif on the $\mathrm{Cl}-\mathrm{HCO}_{3}$ exchanger AE1. The C-termini of all the three NBCel splice variants have two similar DADD motifs [47]. CA II interacts with NBCel-A/B in vitro [48]. Although CA II is adjacent to the C-terminus of NBCel-A, it fails to enhance NBCe1-A activity in oocytes [49].

The C-terminus of NBCel is beyond the scope of this review and will not be discussed here. According to its unique N-terminal amino acid sequences, several authors have examined the involvements of regulatory or binding factors $[13,50-53]$. However, this review focuses on N-termini of $\mathrm{NBCel}$ and interaction with potential regulatory factors.

\section{Roles of Potential Regulatory Factors on the Regulation of NBCe1-B}

4.1. IRBIT. Inositol $1,4,5$-trisphosphate $\left(\mathrm{IP}_{3}\right)$ receptor $\left(\mathrm{IP}_{3} \mathrm{R}\right)$ binding protein released with $\mathrm{IP}_{3}$, called IRBIT, was first identified by Mikoshiba's group [54]. IRBIT binds $\mathrm{IP}_{3} \mathrm{R}$ in the resting state and dissociates from $I_{3} R$ in the stimulated state. Mikoshiba et al. attempted to identify the molecules targeted by IRBIT and focused on an immunoprecipitated protein. The sequence of extracted protein matched that of NBCel protein, and IRBIT was found to bind the NBCelB specifically but not the A variant [55]. Subsequently, they focused on the $\mathrm{N}$ - and C-termini of NBCel-B for IRBIT binding because it was considered that the cytosolic domain of NBCel-B might contain a region that interacts with IRBIT, which is a cytosolic protein. Surprisingly, their pull-down assay revealed that the 85 amino acids' sequence of the $\mathrm{N}$ terminus NBCel-B is sufficient to bind IRBIT. To identify the IRBIT binding region in the N-terminus of NBCe1-B, they prepared deletion mutants encoding different regions of the N-terminus. This terminus possesses a cluster of negatively charged residues (regions 2-24) and a cluster of positively charged residues (regions 37-59) [56]. Deletion mutants were found to bind IRBIT when both positive and negative charged clusters were present. The authors suggested that IRBIT to NBCe1-B binding might require the 3D structure of the $\mathrm{N}$ terminus of NBCe1-B [55]. On the other hand, Yang et al. [13] showed deletion of PEST domain was enough to prevent IRBIT to NBCel-B binding. This domain is a peptide sequence containing many glutamic acids and is negatively charged. The charged nature of this cluster indicates that cluster interacts with the negatively charged PEST domain of IRBIT. In addition, another member of the $\mathrm{Na}^{+}$-derived $\mathrm{HCO}_{3}{ }^{-}$transporters such as NBCnl-A has an N-terminal domain similar to that of NBCe1-B, which revealed that its activity was modulated by IRBIT [50]. 
4.2. Phosphatidylinositol 4,5-Bisphosphate (PIP2). Phospholipids are ubiquitous and act as powerful signaling molecules. Beyond its classic functions, such as acting as a precursor for inositol triphosphate $\left(\mathrm{IP}_{3}\right)$ and diacylglycerol, several reports have showed that phosphatidylinositol 4,5-bisphosphate (PIP2) activates diverse processes, including $\mathrm{K}_{\mathrm{ATP}}$ channel $[57,58]$ and NHE1 [59]. More recently, inside-out macropatch experiments showed PIP2 stimulated NBCel-A activity in xenopus oocytes [44]. In the presence of poly-D-lysine or neomycin, only small PIP2-induced inward current was elicited, but PIP2-induced inward current was reestablished after removing neomycin [44]. These data represent the fact that the positive $\mathrm{N}$-terminus clusters of NBCel-B and -C variants may interact with PIP2 to inhibit automodulation of AID domain. PIP2 hydrolysis indirectly stimulates NBCel$\mathrm{B}$ and NBCel-C by increasing $\mathrm{IP}_{3}$ and $\mathrm{Ca}^{2+}$, which are involved in kinase such as staurosporine-sensitive kinase [60]. Although sites that interact with PIP2 have been reported for several transporters, such as transient receptor potential canonical and P2X channels [61-63], the specific binding site in PIP2 has not been determined. Analysis of the PIP2-binding region of $\mathrm{PH}$ domain-containing proteins indicated that the presence of basic amino acids is needed to interact with the anionic head group of PIP2. In the NCBT family, the potential $\left[\mathrm{K}-\mathrm{X}_{n}-\mathrm{K} / \mathrm{R}-\mathrm{K}\right]$ sequence, characterized by phosphoinositide-binding motif [64], was found to be a conserved cluster of positively charged residues. PIP2 and IRBIT activate NBCel-B in a nonadditive manner due to interaction with the same site within the AID [50]. Not only activity of NBCel-B but also activities of other ion channels such as $K_{\text {ATP }}$ channel and NHE1 can be modulated by the PIP2. It can be considered new therapeutic approaches for pathology of ion channels.

\section{3. $\mathrm{Mg}^{2+}$, Polyvalent Cation, and Other Cytosolic Factors.} $\mathrm{Mg}^{2+}$ plays an indispensable role in diverse biological functions, which include modulations of the activities of enzymes, ion channels, and transporter, and is the second-most abundant intracellular ion after potassium $[65,66] . \mathrm{Mg}^{2+}$ can reduce ion channel currents by blocking channels in a voltage-dependent manner [67] and also associates with the negative charges of phosphoinositides by electrostatic interaction [68]. Recently, intracellular $\mathrm{Mg}^{2+}$ was observed to inhibit NBCel-B currents voltage-independently in cloned NBCel-B expressing mammalian cells and native bovine parotid acinar cells, whereas N-terminus truncated NBCelB mutant was less sensitive to $\mathrm{Mg}^{2+}$ than the wild type [51]. In addition to regulatory role of IRBIT on NBCel-B, the coexpression of AHCYL2 (adenosylhomocysteine hydrolaselike protein 2 or long IRBIT) also reduces affinity for intracellular $\mathrm{Mg}^{2+}$ and subsequent inhibition of NBCel-B currents in $\mathrm{HCO}_{3}{ }^{-}$-depleted conditions [52]. This means that IRBIT, long IRBIT, and $\mathrm{Mg}^{2+}$ can be considered potential secondary effectors of NBCel-B. As mentioned above, polyvalent cations such as neomycin also inhibit recombinant and native currents. These findings may provide clues regarding interaction between $\mathrm{Mg}^{2+}$ and clustered negative charged amino acids of
$\mathrm{N}$-terminus by electrostatic mechanism directly or indirectly. Further studies are needed to prove this hypothesis. Several other cytosolic regulatory or membrane bound factors including actin or enzymes for the cytoskeletal elements may be involved in the regulation of NBC transporters.

4.4. Intracellular $\mathrm{Cl}^{-}$Interacting Motifs. $\mathrm{Cl}^{-}$is a major anion and involves numerous cellular functions responsible for fluid and electrolytes homeostasis. $\mathrm{Cl}^{-}$concentration varies and is determined by the activity of several ion transporters/channels such as $\mathrm{ClC} \mathrm{Cl}^{-}$transporter [69], $\mathrm{Cl}^{-} / \mathrm{HCO}_{3}{ }^{-}$ exchanger [70], and CFTR [31, 71]. Recently, the regulatory role of intracellular $\mathrm{Cl}^{-}$was addressed in electrogenic NBC transporters through the complex modulation of activity [72]. Resting NBCel-B is inhibited by high intracellular $\mathrm{Cl}^{-}$ concentration. The regulatory effect of intracellular $\mathrm{Cl}^{-}$on electrogenic NBC is mediated by $\mathrm{Cl}^{-}$interacting GXXXP motifs. The NBCel-B is mediated by two GXXXP motifs, one of which is unmasked by IRBIT in autoinhibitory module to interact with high affinity for $\mathrm{Cl}^{-}$. During the resting state of intracellular $\mathrm{Cl}^{-}$which is between 5 and $60 \mathrm{mM}$ [73], an activity of NBCel-B modestly operates at around 40\% of highest activity, whereas nonphysiological concentration of $\mathrm{Cl}^{-}$at $140 \mathrm{mM}$ inhibited NBCel-B activity by around $60 \%$. In the presence of IRBIT, high affinity $\mathrm{Cl}^{-}$interacting GXXXP site of NBCel-B is released and observed. Complicated modulation, modulation of IRBIT in AID, or different affinity of $\mathrm{Cl}^{-}$addresses the fact that NBCel-B senses different range of $\mathrm{Cl}^{-}$and has several functional roles as well as saving energy [72]. In addition, sequence analysis of other transporters revealed that $\mathrm{K}^{+}-\mathrm{Cl}^{-}$cotransporter $\mathrm{KCC}, \mathrm{Na}^{+}-\mathrm{Cl}^{-}$cotransporter $\mathrm{NCC}, \mathrm{Na}^{+}-\mathrm{K}^{+}-\mathrm{Cl}^{-}$cotransporter NKCC, epithelial $\mathrm{Na}^{+}$channel ENaC, and solute carrier family $26 \mathrm{~A}$ (SLC26A) transporters also possess GXXXP motif. Further studies will be required to characterize and determine any potential $\mathrm{Cl}^{-}$ regulation to these transporters.

4.5. WNK/SPAK Kinases. The regulation of ion transporters is determined by the WNK (with-no-lysine) and the SPAK (Ste20-related proline/alanine-rich kinase) kinase pathways, which involve scaffolding interaction and phosphorylated state $[73,74]$. WNK and SPAK kinases suppress fluid and $\mathrm{HCO}_{3}{ }^{-}$secretion by inhibiting the surface expression of NBCel-B in pancreatic and parotid secretory ducts, and these pathways stabilize the resting state of secretory duct for $\mathrm{HCO}_{3}{ }^{-}$secretion by reducing the surface expressions of ion transporters, whereas IRBIT dramatically stimulates ductal fluid secretion and reverses the effects of WNKs and SPAK kinases [75]. The convergent regulation of NBCe1-B activity by IRBIT and WNK/SPAK is concentrated on the AID of its $\mathrm{N}$-terminus [50]. SPAK kinase phosphorylates S65 and T49 of NBCel-B within AID, and this T49 phosphorylation is required for regulation of NBCel-B by SPAK. However, the regulation of the reciprocal balance of activated and inhibitory states of NBCel-B by IRBIT and the WNK/SPAK pathways remains to be clarified. 


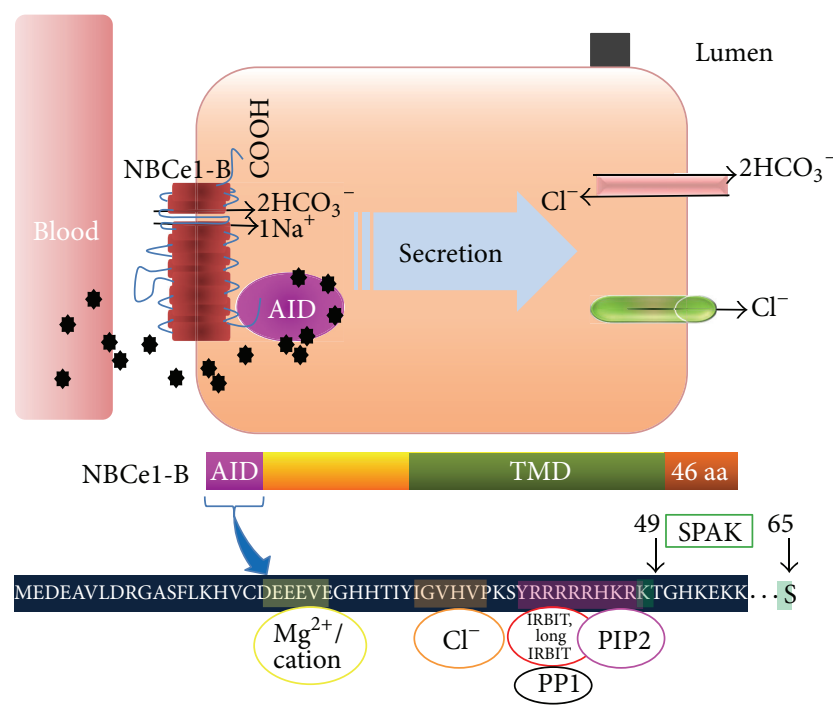

Figure 1: Putative regulatory factors of NBCe1 N-terminal modules. AID domain, TMD domain, and C-terminus are highlighted with magenta, green, and orange color, respectively. Binding motifs are highlighted with similar color background of regulatory factors. SPAK phosphorylation sites are highlighted with green background Tyr49 and Ser65 within N (1-85) terminus. AID: autoinhibitory domain; TMD: transmembrane domain.

\section{Summary}

NBCel-B is a pivotal regulatory protein in $\mathrm{HCO}_{3}{ }^{-}$secreting epithelia, such as those of intestine, lung, pancreas, and salivary glands [31]. As indicated above, several interacting factors are involved in regulation of $\mathrm{NBCel-B}$ for $\mathrm{HCO}_{3}{ }^{-}$ secretion. I focused on the N-terminus of NBCel-B based on the findings of regulatory factors, summarized and illustrated in Figure 1. It will provide particular interests to clarify secretory mechanisms and develop the treatment modalities with nanosized drug and nanomaterial-conjugated regulatory factors. While proteins or enzymes of exogenous origin are attractive for therapeutic applications, their clinical administration has been restricted to the immune response [76]. Therefore protein or enzyme based therapies critically need efficient delivery platforms that protect their degradation through encapsulated carrier platform. The development of promising platform for encapsulating functional biomolecules such as enzymes, phospholipids, and charged ions that can freely diffuse in and out through the pores of nanomaterials may be needed. Moreover the regulatory factor-recruited nanocarrier can be applicable to modulate the activity of overexpressed transporters and subsequently diminish tumor-preferred circumstances in tumorigenesis.

\section{Conflict of Interests}

The author declares that there is no conflict of interests regarding the publication of this paper.

\section{Acknowledgment}

This research was supported by Basic Science Research Program through the National Research Foundation of Korea (NRF) funded by the Ministry of Science, ICT \& Future Planning (2014R1A1A3049477).

\section{References}

[1] W. F. Boron, L. Chen, and M. D. Parker, "Modular structure of sodium-coupled bicarbonate transporters," Journal of Experimental Biology, vol. 212, no. 11, pp. 1697-1706, 2009.

[2] W. F. Boron and E. L. Boulpaep, "Intracellular pH regulation in the renal proximal tubule of the salamander: $\mathrm{Na}-\mathrm{H}$ exchange," Journal of General Physiology, vol. 81, no. 1, pp. 29-52, 1983.

[3] Y. Liu, J.-Y. Xu, D.-K. Wang, L. Wang, and L.-M. Chen, "Cloning and identification of two novel NBCel splice variants from mouse reproductive tract tissues: a comparative study of NCBT genes," Genomics, vol. 98, no. 2, pp. 112-119, 2011.

[4] N. Abuladze, M. Song, A. Pushkin et al., "Structural organization of the human $\mathrm{NBCl}$ gene: $\mathrm{kNBCl}$ is transcribed from an alternative promoter in intron 3," Gene, vol. 251, no. 2, pp. 109$122,2000$.

[5] N. Abuladze, I. Lee, D. Newman, J. Hwang, A. Pushkin, and I. Kurtz, "Axial heterogeneity of sodium-bicarbonate cotransporter expression in the rabbit proximal tubule," The American Journal of Physiology—Renal Physiology, vol. 274, no. 3, pp. F628-F633, 1998.

[6] M. F. Romero, C. M. Fulton, and W. F. Boron, "The SLC4 family of $\mathrm{HCO}_{3}^{-}$transporters," Pflugers Archiv European Journal of Physiology, vol. 447, no. 5, pp. 495-509, 2004.

[7] M. Soleimani, S. M. Grassl, and P. S. Aronson, "Stoichiometry of $\mathrm{Na}^{+}-\mathrm{HCO}-3$ cotransport in basolateral membrane vesicles isolated from rabbit renal cortex," The Journal of Clinical Investigation, vol. 79, no. 4, pp. 1276-1280, 1987.

[8] E. Gross, K. Hawkins, N. Abuladze et al., "The stoichiometry of the electrogenic sodium bicarbonate cotransporter $\mathrm{NBC1}$ is cell-type dependent," Journal of Physiology, vol. 531, part 3, pp. 597-603, 2001.

[9] S. Müller-Berger, O. Ducoudret, A. Diakov, and E. Frömter, "The renal $\mathrm{Na}-\mathrm{HCO}_{3}$-cotransporter expressed in Xenopus laevis oocytes: change in stoichiometry in response to elevation of cytosolic $\mathrm{Ca}^{2+}$ concentration," Pflügers Archiv, vol. 442, no. 5, pp. 718-728, 2001.

[10] E. Gross, K. Hawkins, A. Pushkin et al., "Phosphorylation of ser(982) in the sodium bicarbonate cotransporter kNBC1 shifts the $\mathrm{HCO}(3)(-): \mathrm{Na}(+)$ stoichiometry from $3: 1$ to $2: 1$ in murine proximal tubule cells," Journal of Physiology, vol. 537, no. 3, pp. 659-665, 2001.

[11] H. Zhao, R. A. Star, and S. Muallem, "Membrane localization of $\mathrm{H}^{+}$and $\mathrm{HCO}_{3}^{-}$transporters in the rat pancreatic duct," Journal of General Physiology, vol. 104, no. 1, pp. 57-85, 1994.

[12] C. R. Marino, V. Jeanes, W. F. Boron, and B. M. Schmitt, "Expression and distribution of the $\mathrm{Na}(+)-\mathrm{HCO}(-)(3)$ cotransporter in human pancreas," The American Journal of PhysiologyGastrointestinal and Liver Physiology, vol. 277, no. 2, pp. G487G494, 1999.

[13] D. Yang, N. Shcheynikov, W. Zeng et al., "IRBIT coordinates epithelial fluid and $\mathrm{HCO}_{3}^{-}$secretion by stimulating the transporters $\mathrm{pNBCl}$ and CFTR in the murine pancreatic duct," Journal of Clinical Investigation, vol. 119, no. 1, pp. 193-202, 2009. 
[14] N. Abuladze, I. Lee, D. Newman et al., "Molecular cloning, chromosomal localization, tissue distribution, and functional expression of the human pancreatic sodium bicarbonate cotransporter," The Journal of Biological Chemistry, vol. 273, no. 28, pp. 17689-17695, 1998.

[15] D. Majumdar, A. B. Maunsbach, J. J. Shacka et al., "Localization of electrogenic $\mathrm{Na}$ /bicarbonate cotransporter NBCel variants in rat brain," Neuroscience, vol. 155, no. 3, pp. 818-832, 2008.

[16] M. O. Bevensee, B. M. Schmitt, I. Choi, M. F. Romero, and W. F. Boron, "An electrogenic $\mathrm{Na}(+)-\mathrm{HCO}(-)(3)$ cotransporter (NBC) with a novel $\mathrm{COOH}$-terminus, cloned from rat brain," The American Journal of Physiology-Cell Physiology, vol. 278, no. 6, pp. C1200-C1211, 2000.

[17] E. Gross, N. Abuladze, A. Pushkin, I. Kurtz, and C. U. Cotton, "The stoichiometry of the electrogenic sodium bicarbonate cotransporter $\mathrm{pNBCl}$ in mouse pancreatic duct cells is $2 \mathrm{HCO}_{3}^{-}: 1$ $\mathrm{Na}^{+}$," Journal of Physiology, vol. 531, no. 2, pp. 375-382, 2001.

[18] K. Yoshitomi, B.-C. Burckhardt, and E. Frömter, "Rheogenic sodium-bicarbonate cotransport in the peritubular cell membrane of rat renal proximal tubule," Pflügers Archiv European Journal of Physiology, vol. 405, no. 4, pp. 360-366, 1985.

[19] G. Seki, S. Coppola, and E. Frömter, "The $\mathrm{Na}^{+}-\mathrm{HCO}_{3}^{-}$cotransporter operates with a coupling ratio of $2 \mathrm{HCO}_{3}^{-}$to $1 \mathrm{Na}^{+}$in isolated rabbit renal proximal tubule," Pflügers Archiv European Journal of Physiology, vol. 425, no. 5-6, pp. 409-416, 1993.

[20] X. Luo, J. Y. Choi, S. B. H. Ko et al., " $\mathrm{HCO}_{3}^{-}$salvage mechanisms in the submandibular gland acinar and duct cells," The Journal of Biological Chemistry, vol. 276, no. 13, pp. 9808-9816, 2001.

[21] J. Li, N.-Y. Koo, I.-H. Cho et al., "Expression of the $\mathrm{Na}^{+}-$ $\mathrm{HCO}_{3}^{-}$cotransporter and its role in pHi regulation in guinea pig salivary glands," The American Journal of PhysiologyGastrointestinal and Liver Physiology, vol. 291, no. 6, pp. G1031G1040, 2006.

[22] C. Perry, D. O. Quissell, M. E. Reyland, and I. I. Grichtchenko, "Electrogenic NBCe1 (SLC4A4), but not electroneutral NBCn1 (SLC4A7), cotransporter undergoes cholinergic-stimulated endocytosis in salivary ParC5 cells," The American Journal of Physiology-Cell Physiology, vol. 295, no. 5, pp. C1385-C1398, 2008.

[23] D. Bok, M. J. Schibler, A. Pushkin et al., "Immunolocalization of electrogenic sodium-bicarbonate cotransporters $\mathrm{pNBC1}$ and kNBC1 in the rat eye," The American Journal of PhysiologyRenal Physiology, vol. 281, no. 5, pp. F920-F935, 2001.

[24] O. Bachmann, H. Rossmann, U. V. Berger et al., "cAMP-mediated regulation of murine intestinal/pancreatic $\mathrm{Na}^{+} / \mathrm{HCO}_{3}{ }^{-}$ cotransporter subtype pNBC1," The American Journal of Physiology-Gastrointestinal and Liver Physiology, vol. 284, no. 1, pp. G37-G45, 2003.

[25] O. Bachmann, "Carbachol increases $\mathrm{Na}^{+}-\mathrm{HCO}_{3}^{-}$cotransport activity in murine colonic crypts in a $\mathrm{M}_{3}^{-}, \mathrm{Ca}^{2+} /$ calmodulin-, and PKC-dependent manner," AJP: Gastrointestinal and Liver Physiology, vol. 291, no. 4, pp. G650-G657, 2006.

[26] R. L. Jakab, A. M. Collaco, and N. A. Ameen, "Physiological relevance of cell-specific distribution patterns of CFTR, NKCC1, NBCe1, and NHE3 along the crypt-villus axis in the intestine," The American Journal of Physiology-Gastrointestinal and Liver Physiology, vol. 300, no. 1, pp. G82-G98, 2011.

[27] R. D. Vaughan-Jones, F. C. Villafuerte, P. Swietach, T. Yamamoto, A. Rossini, and K. W. Spitzer, "pH-regulated $\mathrm{Na}^{+}$ influx into the mammalian ventricular myocyte: the relative role of $\mathrm{Na}^{+}-\mathrm{H}^{+}$exchange and $\mathrm{Na}^{+}-\mathrm{HCO}_{3}^{-}$co-transport," Journal of Cardiovascular Electrophysiology, vol. 17, supplement 1, pp. S134-S140, 2006.

[28] R. S. Lacruz, A. Nanci, S. N. White et al., "The sodium bicarbonate cotransporter (NBCel) is essential for normal development of mouse dentition," The Journal of Biological Chemistry, vol. 285, no. 32, pp. 24432-24438, 2010.

[29] L. Zheng, Y. Zhang, P. He et al., "NBCel in mouse and human ameloblasts may be indirectly regulated by fluoride," Journal of Dental Research, vol. 90, no. 6, pp. 782-787, 2011.

[30] J. L. Kreindler, K. W. Peters, R. A. Frizzell, and R. J. Bridges, "Identification and membrane localization of electrogenic sodium bicarbonate cotransporters in Calu-3 cells," Biochimica et Biophysica Acta, vol. 1762, no. 7, pp. 704-710, 2006.

[31] M. G. Lee, E. Ohana, H. W. Park, D. Yang, and S. Muallem, "Molecular mechanism of pancreatic and salivary gland fluid and $\mathrm{HCO}_{3}^{-}$secretion," Physiological Reviews, vol. 92, no. 1, pp. 39-74, 2012.

[32] E. Y. Kim, J. S. Choi, K. E. Lee et al., "Altered regulation of renal acid base transporters in response to ammonium chloride loading in rats," Korean Journal of Physiology and Pharmacology, vol. 16, no. 2, pp. 91-95, 2012.

[33] J. C. Fantinelli, A. Orlowski, E. A. Aiello, and S. M. Mosca, "The electrogenic cardiac sodium bicarbonate co-transporter (NBCel) contributes to the reperfusion injury," Cardiovascular Pathology, vol. 23, no. 4, pp. 224-230, 2014.

[34] W. K. Bae, J. U. Lee, J. W. Park et al., "Decreased expression of $\mathrm{Na}^{+} / \mathrm{K}^{+}$-ATPase, NHE3, NBC1, AQP1 and OAT in gentamicininduced nephropathy," Korean Journal of Physiology and Pharmacology, vol. 12, no. 6, pp. 331-336, 2008.

[35] T. Igarashi, J. Inatomi, T. Sekine et al., "Mutations in SLC4A4 cause permanent isolated proximal renal tubular acidosis with ocular abnormalities," Nature Genetics, vol. 23, no. 3, pp. 264266, 1999.

[36] D. Dinour, M.-H. Chang, J.-I. Satoh et al., "A novel missense mutation in the sodium bicarbonate cotransporter (NBCe1/SLC4A4) causes proximal tubular acidosis and glaucoma through ion transport defects," The Journal of Biological Chemistry, vol. 279, no. 50, pp. 52238-52246, 2004.

[37] P. Gross and C. Meye, "Proximal RTA: are all the charts completed yet?” Nephrology Dialysis Transplantation, vol. 23, no. 4, pp. 1101-1102, 2008.

[38] T. Usui, M. Hara, H. Satoh et al., "Molecular basis of ocular abnormalities associated with proximal renal tubular acidosis," Journal of Clinical Investigation, vol. 108, no. 1, pp. 107-115, 2001.

[39] M. Nakamura, A. Shirai, O. Yamazaki et al., "Roles of renal proximal tubule transport in acid/base balance and blood pressure regulation," BioMed Research International, vol. 2014, Article ID 504808, 7 pages, 2014.

[40] M. S. Soyfoo, N. Bulur, M. Virreira et al., "Expression of the electrogenic na ${ }^{+}-\mathrm{HCO}_{3}^{-}$-cotransporters NBCe1-A and NBCe1$\mathrm{B}$ in rat pancreatic islet cells," Endocrine, vol. 35, no. 3, pp. 449458, 2009.

[41] O. S. Ruiz, Y.-Y. Qiu, L. R. Cardoso, and J. A. L. Arruda, "Regulation of the renal $\mathrm{Na}-\mathrm{HCO}_{3}$ cotransporter: IX. Modulation by insulin, epidermal growth factor and carbachol," Regulatory Peptides, vol. 77, no. 1-3, pp. 155-161, 1998.

[42] R. Jalali, J. Guo, B. Zandieh-Doulabi et al., "NBCe1 $\left(\mathrm{SLC}_{4} \mathrm{~A}_{4}\right)$ a potential $\mathrm{pH}$ regulator in enamel organ cells during enamel development in the mouse," Cell and Tissue Research, vol. 358, no. 2, pp. 433-442, 2014. 
[43] S. D. McAlear, X. Liu, J. B. Williams, C. M. McNicholas-Bevensee, and M. O. Bevensee, "Electrogenic $\mathrm{Na} / \mathrm{HCO}_{3}$ cotransporter (NBCel) variants expressed in Xenopus oocytes: functional comparison and roles of the amino and carboxy termini," Journal of General Physiology, vol. 127, no. 6, pp. 639-658, 2006.

[44] J. Wu, C. M. McNicholas, and M. O. Bevensee, "Phosphatidylinositol 4,5-bisphosphate $\left(\mathrm{PIP}_{2}\right)$ stimulates the electrogenic $\mathrm{Na} / \mathrm{HCO}_{3}$ cotransporter NBCel-A expressed in Xenopus oocytes," Proceedings of the National Academy of Sciences of the United States of America, vol. 106, no. 33, pp. 14150-14155, 2009.

[45] H. M. Becker and J. W. Deitmer, "Carbonic anhydrase II increases the activity of the human electrogenic $\mathrm{Na}^{+} / \mathrm{HCO}_{3}^{-}$ cotransporter," The Journal of Biological Chemistry, vol. 282, no. 18, pp. 13508-13521, 2007.

[46] P. M. Piermarini, E. Y. Kim, and W. F. Boron, "Evidence against a direct interaction between intracellular carbonic anhydrase II and pure C-terminal domains of $\mathrm{SLC}_{4}$ bicarbonate transporters," The Journal of Biological Chemistry, vol. 282, no. 2, pp. 1409-1421, 2007.

[47] J. W. Vince, U. Carlsson, and R. A. Reithmeier, "Localization of the $\mathrm{Cl}^{-} / \mathrm{HCO}_{3}{ }^{-}$anion exchanger binding site to the aminoterminal region of carbonic anhydrase II," Biochemistry, vol. 39, no. 44, pp. 13344-13349, 2000.

[48] E. Gross, A. Pushkin, N. Abuladze, O. Fedotoff, and I. Kurtz, "Regulation of the sodium bicarbonate cotransporter kNBC1 function: role of $\mathrm{Asp}^{986}, \mathrm{Asp}^{988}$ and $\mathrm{kNBC1}$-carbonic anhydrase II binding," Journal of Physiology, vol. 544, no. 3, pp. 679-685, 2002.

[49] J. Lu, C. M. Daly, M. D. Parker et al., "Effect of human carbonic anhydrase II on the activity of the human electrogenic $\mathrm{Na} / \mathrm{HCO}_{3}$ cotransporter NBCel-A in Xenopus oocytes," The Journal of Biological Chemistry, vol. 281, no. 28, pp. 19241-19250, 2006.

[50] J. H. Hong, D. Yang, N. Shcheynikov, E. Ohana, D. M. Shin, and S. Muallem, "Convergence of IRBIT, phosphatidylinositol $(4,5)$ bisphosphate, and WNK/SPAK kinases in regulation of the $\mathrm{Na}^{+}-\mathrm{HCO}_{3}{ }^{-}$cotransporters family," Proceedings of the National Academy of Sciences of the United States of America, vol. 110, no. 10, pp. 4105-4110, 2013.

[51] S. Yamaguchi and T. Ishikawa, "The electrogenic $\mathrm{Na}^{+}-\mathrm{HCO}_{3}{ }^{-}$ cotransporter NBCel-B is regulated by intracellular $\mathrm{Mg}^{2+}$," Biochemical and Biophysical Research Communications, vol. 376, no. 1, pp. 100-104, 2008.

[52] S. Yamaguchi and T. Ishikawa, "AHCYL2 (long-IRBIT) as a potential regulator of the electrogenic $\mathrm{Na}^{+}-\mathrm{HCO}_{3}{ }^{-}$cotransporter NBCel-B," FEBS Letters, vol. 588, no. 5, pp. 672-677, 2014.

[53] S.-K. Lee, W. F. Boron, and M. D. Parker, "Relief of autoinhibition of the electrogenic $\mathrm{Na}-\mathrm{HCO}_{3}$ cotransporter NBCel-B: role of IRBIT vs. amino-terminal truncation," The American Journal of Physiology-Cell Physiology, vol. 302, no. 3, pp. C518-C526, 2012.

[54] H. Ando, A. Mizutani, T. Matsu-ura, and K. Mikoshiba, "IRBIT, a novel inositol 1,4,5-trisphosphate (IP3) receptor-binding protein, is released from the IP3 receptor upon IP3 binding to the receptor," The Journal of Biological Chemistry, vol. 278, no. 12, pp. 10602-10612, 2003.

[55] K. Shirakabe, G. Priori, H. Yamada et al., "IRBIT, an inositol 1,4,5-trisphosphate receptor-binding protein, specifically binds to and activates pancreas-type $\mathrm{Na}^{+} / \mathrm{HCO}_{3}{ }^{-}$cotransporter 1 (pNBC1)," Proceedings of the National Academy of Sciences, vol. 103, no. 25, pp. 9542-9547, 2006.
[56] D. Yang, N. Shcheynikov, and S. Muallem, "IRBIT: it is everywhere," Neurochemical Research, vol. 36, no. 7, pp. 1166-1174, 2011.

[57] D. W. Hilgemann and R. Ball, "Regulation of cardiac $\mathrm{Na}^{+}, \mathrm{Ca}^{2+}$ exchange and K(ATP) potassium channels by PIP2," Science, vol. 273, no. 5277, pp. 956-959, 1996.

[58] Z. He, S. Feng, Q. Tong, D. W. Hilgemann, and K. D. Philipson, "Interaction of PIP2 with the XIP region of the cardiac $\mathrm{Na} / \mathrm{Ca}$ exchanger," The American Journal of Physiology-Cell Physiology, vol. 278, no. 4, pp. C661-C666, 2000.

[59] O. Aharonovitz, H. C. Zaun, T. Balla, J. D. York, J. Orlowski, and S. Grinstein, "Intracellular $\mathrm{pH}$ regulation by $\mathrm{Na}^{+} / \mathrm{H}^{+}$exchange requires phosphatidylinositol 4,5-bisphosphate," Journal of Cell Biology, vol. 150, no. 1, pp. 213-224, 2000.

[60] I. M. Thornell, J. Wu, X. Liu, and M. O. Bevensee, "PIP2 hydrolysis stimulates the electrogenic $\mathrm{Na}^{+}$-bicarbonate cotransporter NBCe1-B and -C variants expressed in Xenopus laevis oocytes," Journal of Physiology, vol. 590, no. 23, pp. 5993-6011, 2012.

[61] J. Soboloff, M. Spassova, T. Hewavitharana et al., "TRPC channels: integrators of multiple cellular signals," Handbook of Experimental Pharmacology, vol. 179, pp. 575-591, 2007.

[62] L.-P. Bernier, A. R. Ase, and P. Séguéla, "Post-translational regulation of P2X receptor channels: modulation by phospholipids," Frontiers in Cellular Neuroscience, vol. 7, article 226, 2013.

[63] L.-P. Bernier, D. Blais, É. Boué-Grabot, and P. Séguéla, "A dual polybasic motif determines phosphoinositide binding and regulation in the P2X channel family," PLoS ONE, vol. 7, no. 7, Article ID e40595, 2012.

[64] B. Sims, D. K. Mahnke-Zizelman, A. A. Profit, G. D. Prestwich, R. L. Sabina, and A. B. Theibert, "Regulation of AMP deaminase by phosphoinositides," The Journal of Biological Chemistry, vol. 274, no. 36, pp. 25701-25707, 1999.

[65] A. Romani, "Regulation of magnesium homeostasis and transport in mammalian cells," Archives of Biochemistry and Biophysics, vol. 458, no. 1, pp. 90-102, 2007.

[66] C. Schmitz, F. Deason, and A.-L. Perraud, "Molecular components of vertebrate $\mathrm{Mg}^{2+}$-homeostasis regulation," Magnesium Research, vol. 20, no. 1, pp. 6-18, 2007.

[67] C. G. Nichols and A. N. Lopatin, "Inward rectifier potassium channels," Annual Review of Physiology, vol. 59, pp. 171-191, 1997.

[68] B.-C. Suh and B. Hille, "Electrostatic interaction of internal $\mathrm{Mg}^{2+}$ with membrane PIP2 seen with KCNQ $\mathrm{K}^{+}$channels," Journal of General Physiology, vol. 130, no. 3, pp. 241-256, 2007.

[69] R. Dutzler, E. B. Campbell, M. Cadene, B. T. Chait, and R. MacKinnon, "X-ray structure of a CIC chloride channel at $3.0 \AA$ reveals the molecular basis of anion selectivity," Nature, vol. 415, no. 6869, pp. 287-294, 2002.

[70] M. Yamaguchi, H. Ishiguro, M. Steward et al., "Apical Cl$/ \mathrm{HCO}_{3}^{-}$exchanger stoichiometry in the modeling of $\mathrm{HCO}_{3}^{-}$ transport by pancreatic duct epithelium," The Journal of Medical Investigation, vol. 56, supplement, pp. 325-328, 2009.

[71] H. W. Park, J. H. Nam, J. Y. Kim et al., "Dynamic regulation of CFTR bicarbonate permeability by $\left[\mathrm{Cl}^{-}\right]_{i}$ and its role in pancreatic bicarbonate secretion," Gastroenterology, vol. 139, no. 2, pp. 620-631, 2010.

[72] N. Shcheynikov, A. Son, J. H. Hong et al., "Intracellular $\mathrm{Cl}^{-}$as a signaling ion that potently regulates $\mathrm{Na}^{+} / \mathrm{HCO}^{-}$transporters," Proceedings of the National Academy of Sciences of the United States of America, vol. 112, no. 3, pp. E329-E337, 2015.

[73] K. T. Kahle, A. M. Ring, and R. P. Lifton, "Molecular physiology of the WNK kinases," Annual Review of Physiology, vol. 70, pp. 329-355, 2008. 
[74] C. Richardson and D. R. Alessi, "The regulation of salt transport and blood pressure by the WNK-SPAK/OSR1 signalling pathway," Journal of Cell Science, vol. 121, no. 20, pp. 3293-3304, 2008.

[75] D. Yang, Q. Li, I. So et al., "IRBIT governs epithelial secretion in mice by antagonizing the WNK/SPAK kinase pathway," Journal of Clinical Investigation, vol. 121, no. 3, pp. 956-965, 2011.

[76] I. Ortac, D. Simberg, Y.-S. Yeh et al., "Dual-porosity hollow nanoparticles for the immunoprotection and delivery of nonhuman enzymes," Nano Letters, vol. 14, no. 6, pp. 3023-3032, 2014. 

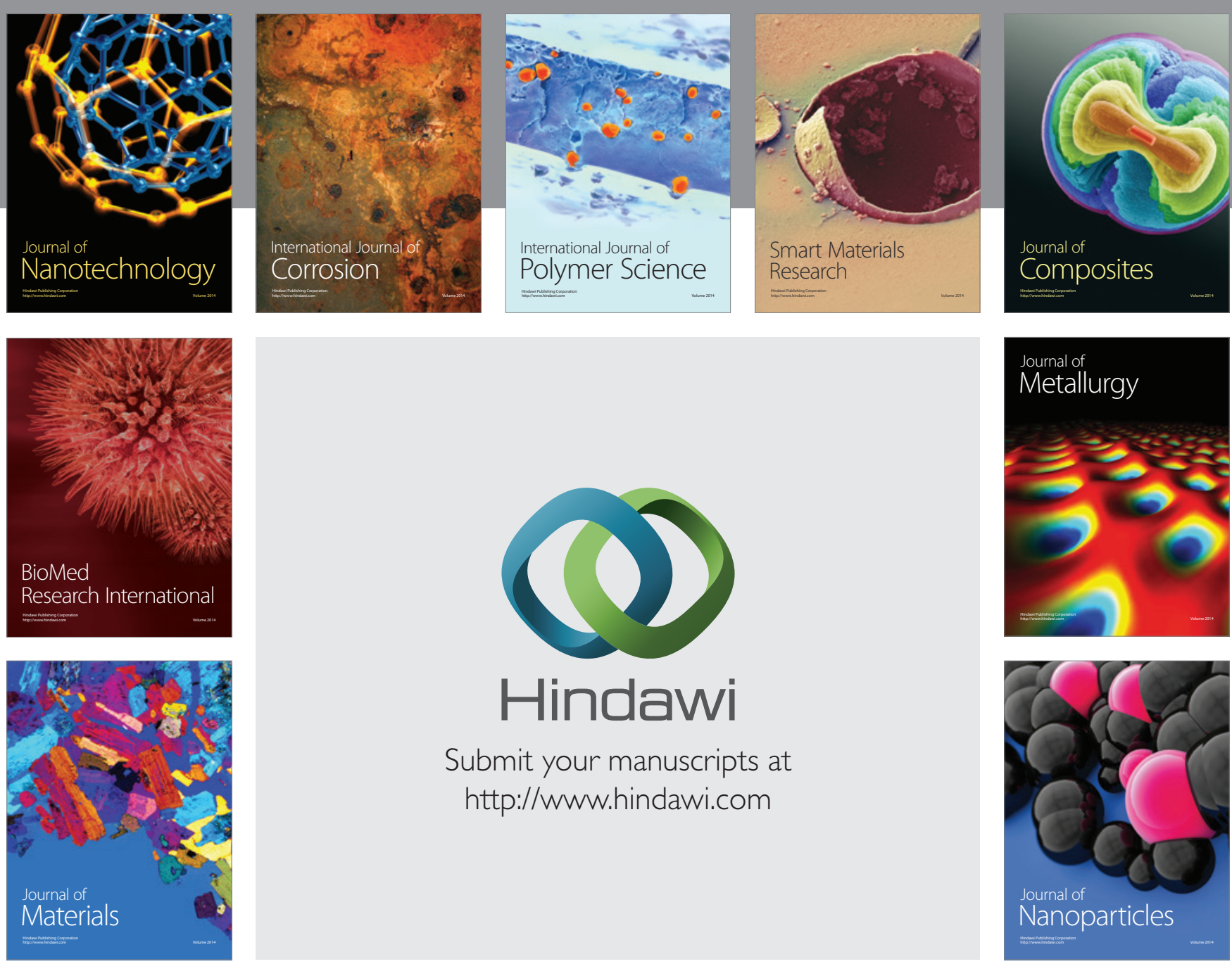

Submit your manuscripts at http://www.hindawi.com
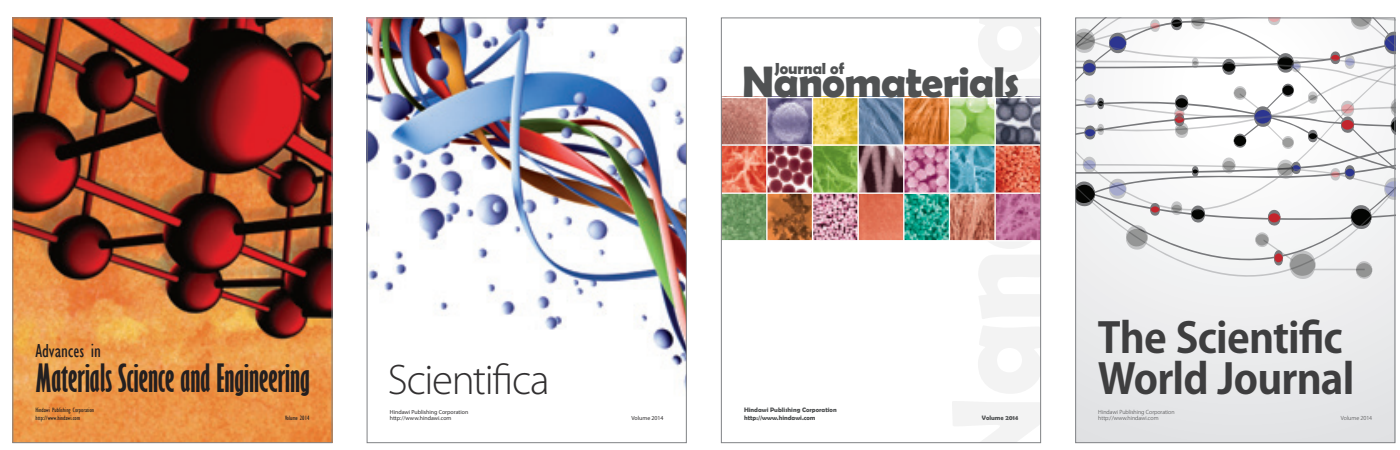

\section{The Scientific World Journal}
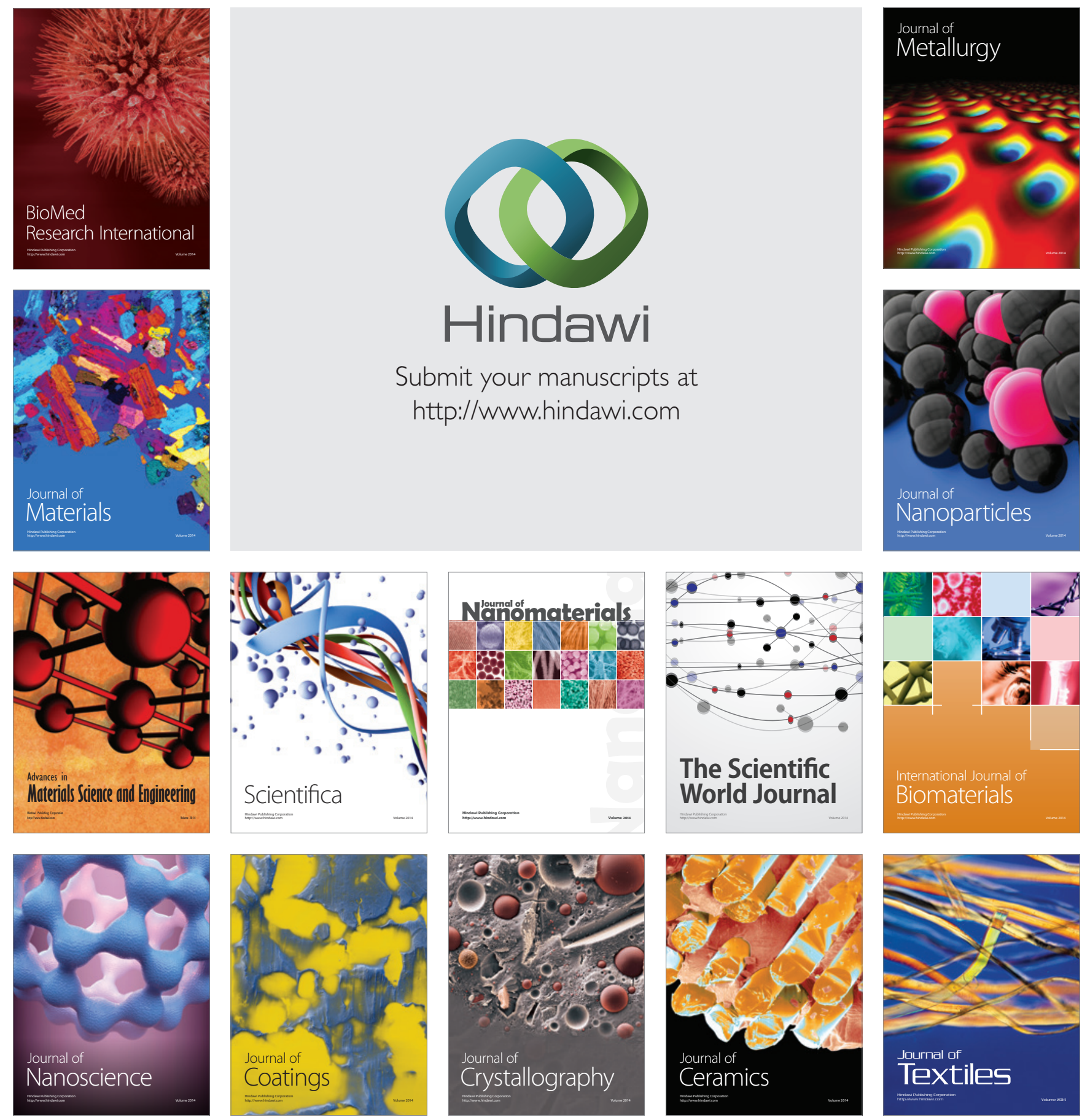